\title{
BMJ Open Smoking-related behaviour changes among Korean men after the 2015 tobacco price increase: assessing the implications for the tobacco endgame using a reconstructed retrospective cohort study
}

\author{
Seulgi Kim (D) , ${ }^{1}$ Sung-il Cho ${ }^{1,2}$
}

To cite: Kim S, Cho S. Smoking-related behaviour changes among Korean men after the 2015 tobacco price increase: assessing the implications for the tobacco endgame using a reconstructed retrospective cohort study. BMJ Open 2022;12:e051712. doi:10.1136/ bmjopen-2021-051712

- Prepublication history for this paper is available online. To view these files, please visit the journal online (http://dx.doi. org/10.1136/bmjopen-2021051712).

Received 29 March 2021 Accepted 22 November 2021

D) Check for updates

(c) Author(s) (or their employer(s)) 2022. Re-use permitted under CC BY-NC. No commercial re-use. See rights and permissions. Published by BMJ.

${ }^{1}$ Graduate School of Public Health, Seoul National University, Seoul, South Korea

${ }^{2}$ Institute of Health and Environment, Seoul National University, Seoul, South Korea

Correspondence to Professor Sung-il Cho; persontime@hotmail.com

\section{ABSTRACT}

Objectives To examine the effect of Korea's 2015 tax policy, discuss its effectiveness and limitations and present future directions for tax policy in the context of the tobacco endgame.

Design A retrospectively reconstructed cohort study. Setting Korea, August 2014-0ctober 2015.

Participants The study examined 41,605 male smokers aged 19 years and older who participated in the 2015 Korea Community Health Survey.

Measures and analysis Binary and multinomial logistic regression was used to assess the impact of the tax policy on smoking-related behaviour. We adjusted for demographic and health-related variables.

Results Among 41,605 men who were smokers in 2014, 15,499 (35.85\%, weighted) reported being affected by the price increase. Of all smokers, 1,772 (3.96\%, weighted) reported quitting smoking because of the tobacco price increase. Others reduced their smoking amount $(n=9,714,22.48 \%$, weighted) or made other changes such as switching brands ( $n=4,013,9.41 \%$, weighted). An additional 2,401 smokers (5.72\%, weighted) quit smoking for reasons other than the tobacco price increase. Compared with those in the highest quintile of household income, the odds that those in the lowest quintile quit smoking due to the price increase were almost twice as high $(0 \mathrm{R}=1.98,95 \% \mathrm{Cl} 1.54$ to 2.54$)$.

Conclusions Korea's 2015 tobacco price increase affected a significant number of smokers within a year, especially in the lowest income group, inducing some to quit or reduce their smoking amount. However, more smokers quit for reasons independent of the price change. Tax policy can effectively reduce smoking, but needs to be combined with other policies for optimal results.

\section{INTRODUCTION}

Since ratification of the WHO Framework Convention on Tobacco Control (FCTC), various policies implemented worldwide to regulate smoking have proven effective. ${ }^{1}$ A tobacco tax increase is a representative
Strengths and limitations of this study

- This study used nationally representative data of male smokers aged 19 years and older.

- The retrospectively reconstructed cohort design enabled assessment of changes in smokers' behaviours after implementation of the tax policy.

- We did not analyse the amount of cigarettes smoked before the price increase, and assessed the changes over a relatively short period (the past year).

policy that contributes to a global decline in smoking; it can also improve health inequalities related to smoking behaviour because smokers with lower income are typically more sensitive to increased cigarette prices. $^{2-5}$

Considerable discussion has occurred about a 'tobacco endgame' or an intensive regulatory strategy to bring the smoking rate closer to zero and ultimately aim for tobacco-free populations. ${ }^{6-8}$ Research on the tobacco endgame requires consideration of the needs of countries in various geographical regions. ${ }^{9}$ Although it may be legally and ethically challenging, the endgame strategy would critically benefit public health. ${ }^{8}$ Lowering smoking prevalence substantially below the current level using conventional means would be difficult. ${ }^{10}$ To achieve the goal of the tobacco endgame, it is necessary to establish new strategies based on evidence gained by reviewing existing policies and obtaining new insights on the effects of conventional tobacco regulation policies. ${ }^{10} 11$ As with any tobacco regulation strategy, tax policy needs to be re-evaluated in terms of its effects on behaviour, and with consideration of the 
additional efforts needed to supplement such policy for the tobacco endgame to be realised. ${ }^{712}$

Korea's most recent tobacco tax policy was implemented in January $2015 .{ }^{13}$ The smoking prevalence rate for men in Korea is one of the highest among (OECD) Organization for Economic Cooperation and Development countries, whereas the tobacco price was the cheapest until 2014. ${ }^{13}$ The price of cigarettes did not increase from 2005 to $2015 .{ }^{1314}$ With the new tax policy, the price of tobacco rose sharply in 2015 (from 2,000 Korean Won [ $\$ 1.68$ USD] to 4,500 Korean Won [ $\$ 3.80$ USD] per pack).

Studies have analysed changes in tobacco use patterns after the recent tax increase in Korea. The cessation rate of smokers increased significantly in $2015,{ }^{15}$ especially among moderate to heavy smokers and those who had the intention to quit. ${ }^{16}$ The smoking amount was particularly reduced among those with lower socioeconomic status and those exposed to antismoking campaigns. ${ }^{17}$ However, few studies have directly compared quitters with non-quitters (among those who smoked before the tax policy) in terms of the effect the price increase. In the Korean Community Health Survey (KCHS), conducted from August to October 2015, participants were asked whether the tobacco price increase affected their smoking-related behaviours. This allowed us to assess the effect of the tax policy on quitting and other smoking behaviours, in comparison with those who continued smoking.

In this study, we examined the effect of Korea's 2015 tax policy, discuss the effectiveness and limitations, and present future directions for tax policy in the framework of the tobacco endgame.

\section{METHODS}

\section{Data and subjects}

This study used data from the KCHS conducted during September-October 2015. The KCHS, conducted yearly since 2008 under the supervision of the Korea Disease Control and Prevention Agency (KDCA), aims to produce primary data about population health among adults aged 19 years and older in each region as a basis for policy-making (dataset) ${ }^{18}$ Subjects in the study were 41,605 adult men who participated in the KCHS in 2015 and answered that they were current smokers $(n=37,256)$ or past smokers whose smoking cessation period was less than 1 year $(n=4,346)$. These participants represented the cohort of current smokers in 2014, reconstructed retrospectively from the 2015 survey.

\section{Patient and public involvement}

This study used secondary data from the KDCA.

\section{Study design}

Retrospective cohort data were reconstructed, as described above. Study subjects were grouped according to whether their smoking behaviour was affected by the tobacco price increase in January 2015, and how their smoking-related behaviours changed after the price increase. Figure 1 shows the study design and sample size.

\section{Measurement}

This study analysed smoking-related variables, including the experience of the tobacco price increase and changes in smoking-related behaviours. The demographic information analysed included monthly household income, age, education level, marital status, household size and residential area, while health-related variables included high-risk drinking, physical activity, the experience of stress and depression and the number of chronic diseases.

Smoking-related variables: all respondents who smoked in 2014 were asked about their experience of the tobacco

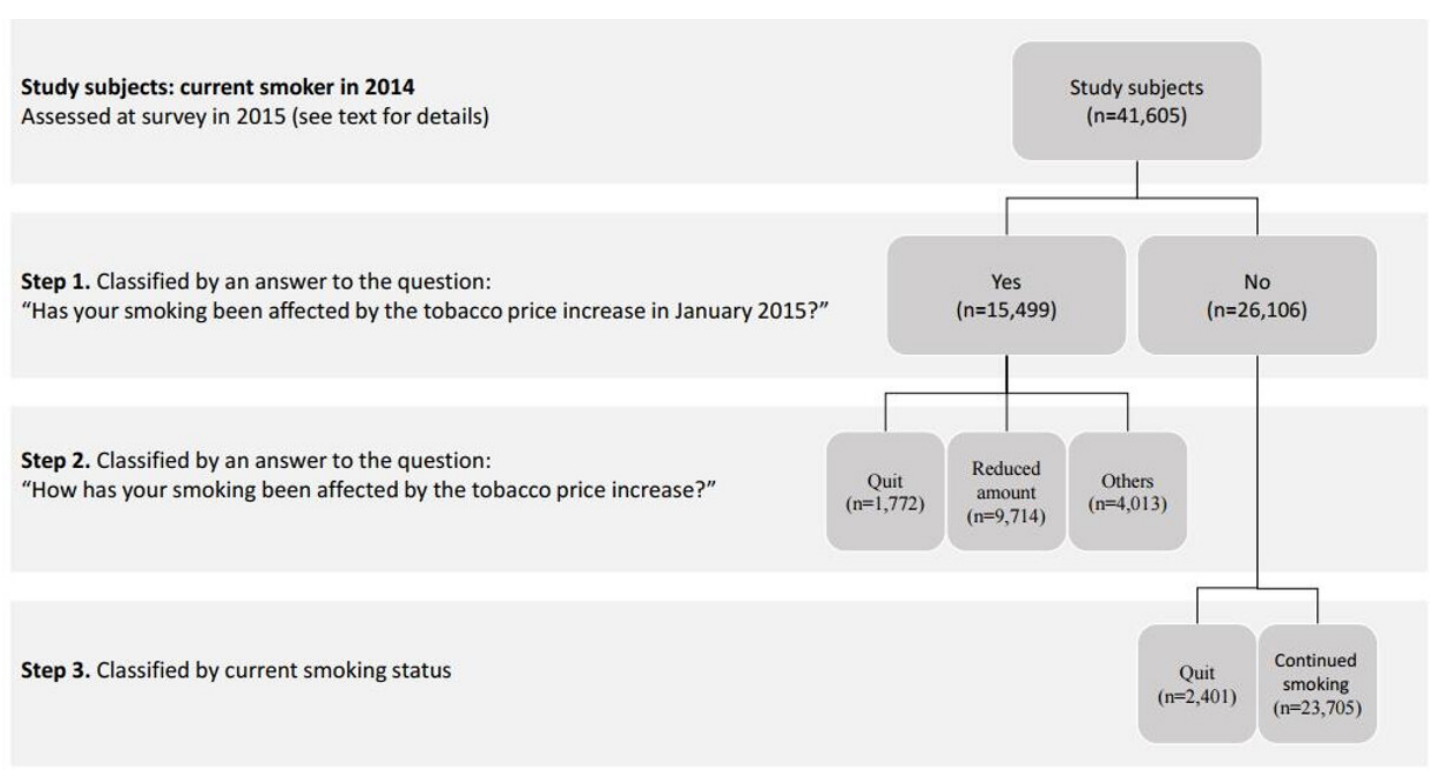

Figure 1 Study design and sample size (file attached). 
price increase using the following question: 'Has your smoking been affected by the tobacco price increase in January 2015?' The response options were 'yes' and 'no'. For those who answered yes, the next question asked, 'How has your smoking been affected by the tobacco price increase?' Responses were grouped into three categories: 'quit smoking', 'reduced smoking amount', and other changes including 'switched to cheaper brands', 'switched to e-cigarettes', 'switched to non-cigarette tobacco products' and 'other'. Regarding smoking status, those who answered No were classified into two groups: unaffected and continued smoking, and unaffected but quit smoking. The respondents were finally classified into five groups by respondents' smoking status and behaviours: (1) affected and quit; (2) affected and reduced smoking amount; (3) affected and changed smoking behaviour in other ways; (4) unaffected but quit smoking; and (5) unaffected and continued smoking (figure 1).

Demographic variables: information was collected on age, monthly household income, educational status, marital status, household size and residential area (urban vs rural). Monthly household income was classified into five categories: less than 1 million Korean Won $(<\$ 845$ USD by 2015 exchange rate), from 1 to 1.99 million Korean Won ( $\$ 845$ USD - \$1,680 USD), from 2 to 2.99 million Korean Won ( $\$ 1,680$ USD - $\$ 2,535$ USD), from 3 to 3.99 million Korean Won (\$2,535 USD - \$3,380 USD) and 4 million Korean Won or more.

Health-related behaviour variables: high-risk alcohol drinking was defined by the following questions: 'Have you drunk in the last year?'; 'How often do you drink?'; 'How many drinks do you drink at a time?' If respondents answered that they drank more than seven glasses at once and drank twice per week during the past year, they were classified in the 'high-risk drinking group'. Physical activity was assessed by whether respondents reported 'regular physical activity' or not. The self-reported stress level was assessed by asking 'How much stress do you feel in your daily life?', which was answered using a 4-point Likert scale including 'A great deal', 'Rather a lot', 'Some' and 'Very little'. Among these, A great deal and Rather a lot were classified as 'High', and Some and Very little were classified as 'Low'. Experience of depression was defined using the question, 'Have you ever felt sad or hopeless for 2 weeks in a row over the past year'. The number of chronic diseases was classified as ' 0 ', ' 1 ' and ' 2 or more' by asking about any diagnosis by a doctor of high blood pressure, diabetes, hypoglycaemic, arthritis, asthma, allergic rhinitis or atopic dermatitis.

\section{Statistical analysis}

Because the KCHS used a complex sampling design, all analyses were conducted using survey weights provided by the KDCA. Descriptive statistics for the participant characteristics were generated. Whether participants were affected by the price increase was the dependent variable in a binary logistic regression model. Changes in smokingrelated behaviours after implementation of the tax policy were categorised into five categories and the distributions were compared according to different variables. Of the five categories, 'unaffected and continued smoking' was used as the reference; the other categories of changes were analysed by multinomial logistic regression. For both the binary and multinomial logistic regression analyses, the results are presented as ORs with 95\% CIs. Doseresponse trends in the associations between income and the dependent variables were tested and expressed as 'p for trend', using monthly household income categories as an ordinal variable after adjusting for other covariates. The SURVEYFREQ and SURVEYLOGISTIC procedures in SAS V.9.4 were used for the respective analyses. ${ }^{19}$

\section{RESULTS}

Table 1 shows the characteristics of subjects organised by whether they were affected by the tax policy or not. The study included 41,605 persons, and weighted percentages were calculated. Of 41,605 participants, 15,499 (35.85\%) respondents said they were affected by the implementation of the tax policy, and 26,106 (64.15\%) said they were not. Concerning monthly household income, 6,117 people $(8.61 \%)$ were in the lowest income group $(<\$ 845$ USD), and 11,681 people $(35.39 \%)$ were in the highest $(\geq \$ 3,380$ USD). By age, the largest category comprised people in their $40 \mathrm{~s},(\mathrm{n}=10,505,26.67 \%)$, and the smallest was those in their $70 \mathrm{~s}(\mathrm{n}=3,659,4.10 \%)$. In terms of education status, $28.07 \%$ of all subjects had graduated from university or higher. Most (65.29\%) people were married and most $(66.87 \%)$ lived with three or more family members. Considering health-related variables, $33.40 \%$ of respondents showed high-risk alcohol consumption, and $25.61 \%$ reported exercising regularly. Moreover, $34.75 \%$ reported higher perceived stress, and $5.81 \%$ reported having experienced depression for more than 2 weeks. However, $61.63 \%$ of respondents said they had no chronic diseases.

Table 2 shows these characteristics with subjects divided into five groups. As table 1 shows, among the 41,605 respondents, $15499(35.85 \%)$ answered that they were affected by the tax policy; the others $(n=26,106,64.15 \%)$ said that they were not. Among those who were affected, 1,772 people answered that they quit smoking because of the tax policy. Another 9,714 respondents reduced their smoking, and 4,013 reported that they changed to a cheaper brand of cigarettes, started using e-cigarettes, or tried other behaviours. Of those who were unaffected, 2401 quit smoking for different reasons, and 23,705 respondents continued smoking without changing their smoking-related behaviours.

Table 3 shows the binary logistic regression analysis results examining associations of responses to the tax policy with demographics and health-related behaviours. The dependent variable was divided into participants who were affected and those who were not. The ORs and 95\% CIs were calculated using the unaffected group as the reference. The analysis showed that 
Table 1 Characteristics of subjects (affected/unaffected)

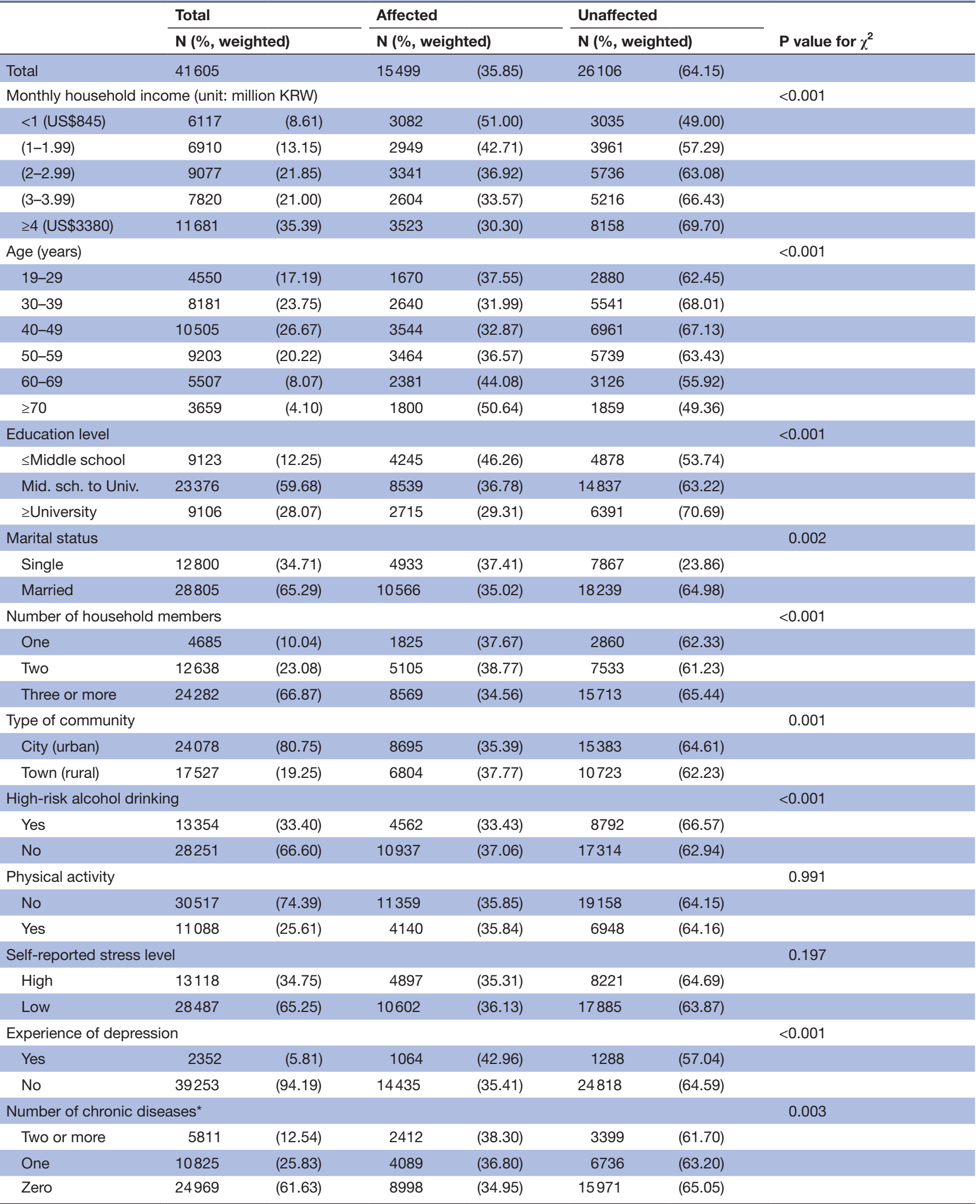

*Doctor-diagnosed high blood pressure, diabetes, hyponatraemia, arthritis, allergens, asthma or atopic dermatitis. 


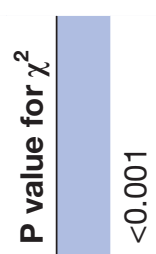

훙

○े

$\overline{8}$
v
v

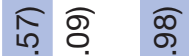

过造

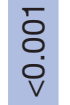

$\bar{\delta}$
0
0

बक्ष

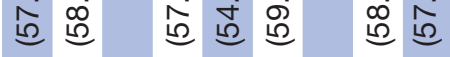

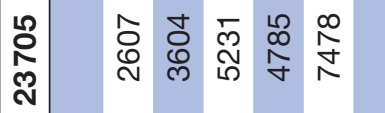

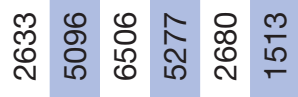

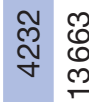

$\underset{\infty}{\infty}$

을

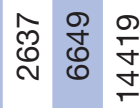

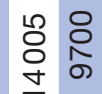

두응

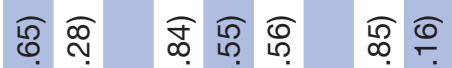

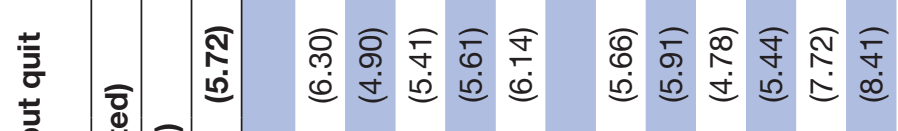

อ ம

e

$\pm 0$

¿

10

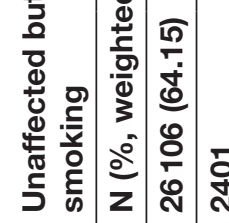

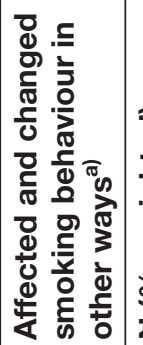

$\frac{m}{q}$

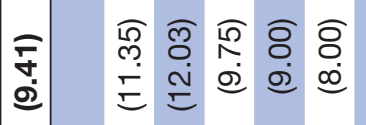

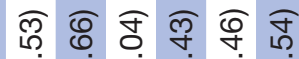

@i $\infty$ 은

ำ 守

จิ จุ

은

న.

E

๙ิ

פ은

$\stackrel{\infty}{\infty}$

ED

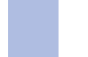

প্নে হ্নে

$\mathscr{L}$
$\stackrel{0}{0}$
$\stackrel{0}{0}$

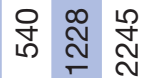

N

व

สำ

๑

응 중

ले

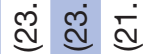

ธิ

్ํำ

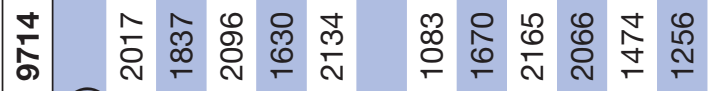

$\stackrel{\stackrel{N}{N}}{\sim}$

ஸి

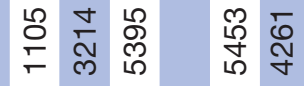

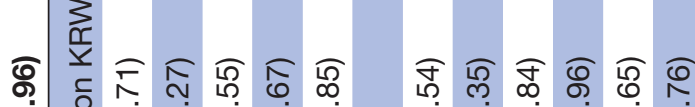

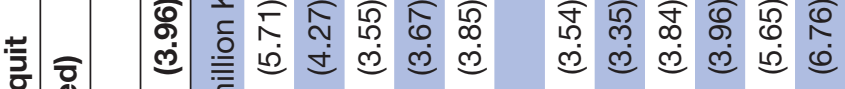

ซิ ซึ क

กิ

娄

மூ लं

लं

ذं

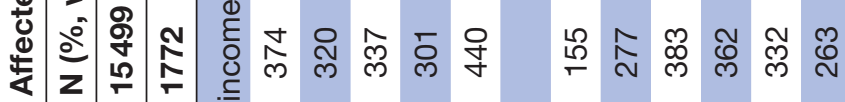

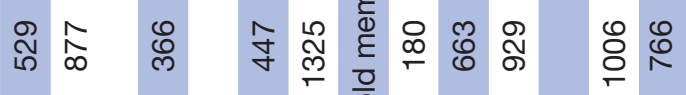

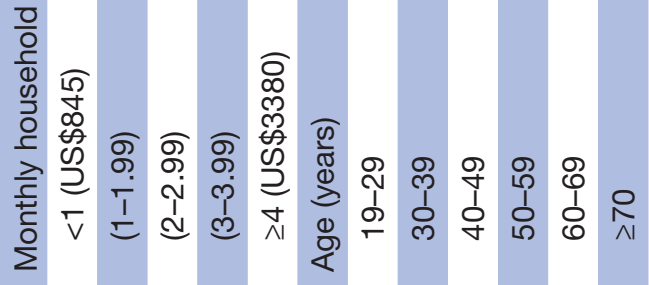

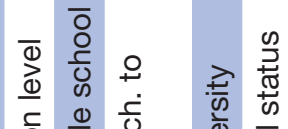

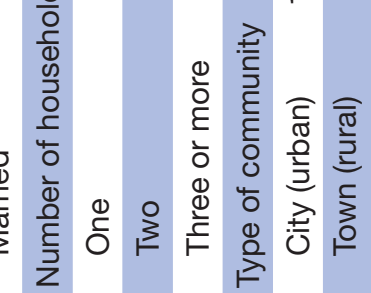

뭉

$\frac{\bar{\sigma}}{\bar{\Phi}}$

๗ 


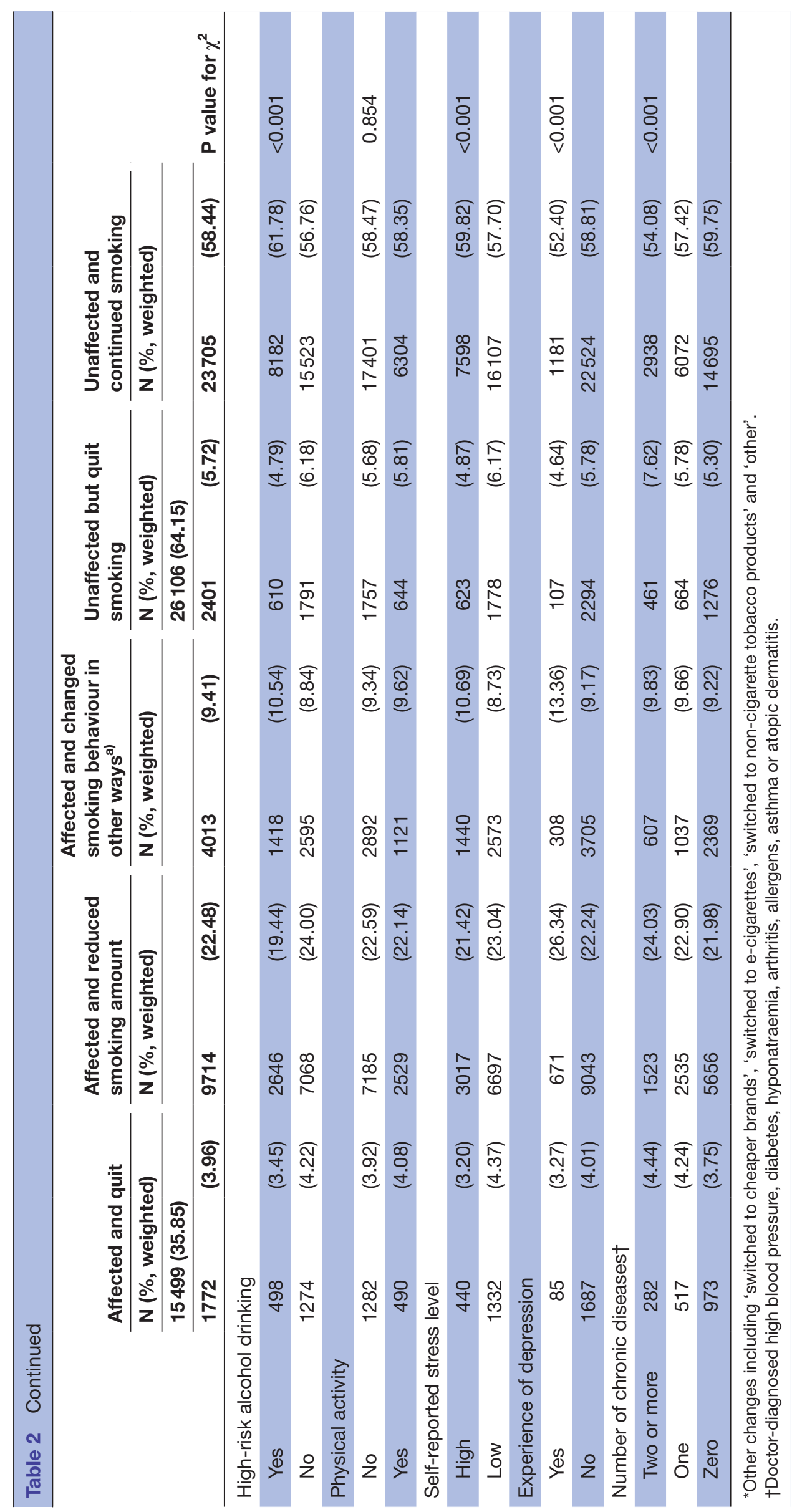


Table 3 Results of binary logistic regression analysis examining associations of the experience of tax policy with demographics and health-related behaviours

\begin{tabular}{|c|c|c|c|c|}
\hline Variables & Crude OR & $(95 \% \mathrm{Cl})$ & \multicolumn{2}{|c|}{ Adjusted OR (95\% Cl) } \\
\hline \multicolumn{5}{|c|}{ Monthly household income (unit: million KRW)* } \\
\hline$<1$ (US\$845) & 2.39 & (2.20 to 2.60$)$ & 1.98 & (1.79 to 2.19$)$ \\
\hline$(1-1.99)$ & 1.72 & (1.59 to 1.86$)$ & 1.54 & (1.41 to 1.68$)$ \\
\hline$(2-2.99)$ & 1.35 & (1.26 to 1.45$)$ & 1.29 & (1.20 to 1.39$)$ \\
\hline$(3-3.99)$ & 1.16 & (1.08 to 1.25$)$ & 1.14 & (1.06 to 1.23$)$ \\
\hline$\geq 4$ (US\$3380) & 1.00 & (Ref) & 1.00 & (Ref) \\
\hline \multicolumn{5}{|l|}{ Age (years) } \\
\hline $19-29$ & 0.59 & (0.52 to 0.66$)$ & 0.83 & (0.72 to 0.97$)$ \\
\hline 30-39 & 0.46 & (0.41 to 0.51$)$ & 0.72 & (0.63 to 0.82$)$ \\
\hline $40-49$ & 0.48 & (0.43 to 0.53$)$ & 0.74 & (0.65 to 0.85$)$ \\
\hline $50-59$ & 0.56 & (0.51 to 0.63$)$ & 0.81 & (0.71 to 0.91$)$ \\
\hline $60-69$ & 0.77 & (0.68 to 0.86$)$ & 0.92 & (0.81 to 1.03$)$ \\
\hline$\geq 70$ & 1.00 & (Ref) & 1.00 & (Ref) \\
\hline \multicolumn{5}{|l|}{ Education level } \\
\hline$\leq$ Middle school & 2.08 & (1.92 to 2.24 ) & 1.43 & (1.30 to 1.58$)$ \\
\hline Mid. sch. to Univ. & 1.40 & (1.32 to 1.49$)$ & 1.26 & (1.18 to 1.34$)$ \\
\hline$\geq$ University & 1.00 & (Ref) & 1.00 & (Ref) \\
\hline \multicolumn{5}{|l|}{ Marital status } \\
\hline Single & 1.11 & (1.05 to 1.17$)$ & 1.03 & (0.96 to 1.10$)$ \\
\hline Married & 1.00 & (Ref) & 1.00 & (Ref) \\
\hline \multicolumn{5}{|c|}{ Number of household members } \\
\hline One & 1.14 & (1.06 to 1.24$)$ & 0.85 & (0.77 to 0.94$)$ \\
\hline Two & 1.20 & (1.13 to 1.27$)$ & 0.93 & (0.87 to 1.00$)$ \\
\hline Three or more & 1.00 & (Ref) & 1.00 & (Ref) \\
\hline \multicolumn{5}{|l|}{ Type of community } \\
\hline City (urban) & 0.90 & (0.86 to 0.95$)$ & 1.03 & (0.97 to 1.09$)$ \\
\hline Town (rural) & 1.00 & (Ref) & 1.00 & (Ref) \\
\hline \multicolumn{5}{|c|}{ High-risk alcohol drinking } \\
\hline Yes & 0.85 & (0.81 to 0.90$)$ & 0.89 & (0.85 to 0.94$)$ \\
\hline No & 1.00 & (Ref) & 1.00 & (Ref) \\
\hline \multicolumn{5}{|l|}{ Physical activity } \\
\hline No & 1.00 & (0.95 to 1.06$)$ & 0.99 & (0.93 to 1.05$)$ \\
\hline Yes & 1.00 & (Ref) & 1.00 & (Ref) \\
\hline \multicolumn{5}{|c|}{ Self-reported stress level } \\
\hline High & 0.97 & (0.92 to 1.02$)$ & 1.00 & (0.95 to 1.06$)$ \\
\hline Low & 1.00 & (Ref) & 1.00 & (Ref) \\
\hline \multicolumn{5}{|c|}{ Experience of depression } \\
\hline Yes & 1.37 & (1.24 to 1.52$)$ & 1.25 & (1.12 to 1.39$)$ \\
\hline No & 1.00 & (Ref) & 1.00 & (Ref) \\
\hline \multicolumn{5}{|c|}{ Number of chronic diseases $\dagger$} \\
\hline Two or more & 1.16 & (1.07 to 1.24$)$ & 1.02 & (0.94 to 1.10$)$ \\
\hline One & 1.08 & (1.03 to 1.15$)$ & 1.04 & (0.98 to 1.10$)$ \\
\hline Zero & 1.00 & (Ref) & 1.00 & (Ref) \\
\hline
\end{tabular}


the lower the household income, the higher the OR of all tiers ( $p$ for trend $<0.001$ ), compared with the highest income group $(\geq \$ 3,380$ USD). The lowest income group $(<\$ 845$ USD) had an especially high OR of 1.98 (CI 1.79 to 2.19). With respect to age, those in their 20s had an OR of 0.83 (CI 0.72 to 0.97 ); for those in their 30 s, it was 0.72 (CI 0.63 to 0.82 ); and for those in their 40s, 0.74 (CI 0.65 to 0.85). Furthermore, those with the lowest education level ( $\leq$ middle school) were more likely to be affected by tax policies. Compared with the group who graduated college or above, the OR was 1.43 (CI 1.30 to 1.58) for middle school graduates and 1.26 (CI 1.18 to 1.34) for high school students. In terms of health-related behaviours, there was a significant difference between the impact of high-risk drinking and experience with depression. Those who reported highrisk drinking had a lower OR value of 0.89 (CI 0.85 to 0.94 ), and the depression group had a higher OR, 1.25 (CI 1.12 to 1.39 ).

Table 4 shows the results of multinomial logistic regression analyses examining associations of changes in smoking behaviours with demographic and healthrelated behaviours compared with the unaffected and continued smoking group. The dependent variables were classified into five groups: 'affected and quit', 'affected and reduced', 'affected and changed smoking behavior in other ways', 'unaffected but quit smoking' and unaffected and continued smoking. ORs and CIs were calculated based on the unaffected and continued smoking group. For monthly household income, those with lower incomes had higher OR values, in a doseresponse fashion, in every category except Unaffected but quit smoking. In particular, for the lowest income group ( $<\$ 845$ USD), the group who reported quitting showed an OR value of 1.98 (CI 1.54 to 2.54); those who reported reducing the amount of smoking had an OR of 2.23 (CI 1.98 to 2.51); for those who changed in other ways, it was 1.69 (CI 1.43 to 2.00); and it was 1.37 (CI 1.11 to 1.68) for those who quit independent of the policy. As for marital status, single people had a lower OR than the married group. The high-risk drinking groups had lower OR values compared with the reference group. Compared with the low-stress group, the high-stress group had a lower OR for quitting, but had a significantly higher OR than the affected and changed smoking behavior in other ways group. People who had experienced depression had significantly higher ORs for changes in the amount of smoking and other behavioural changes.

\section{DISCUSSION}

The 2015 Korean tobacco tax policy significantly affected smokers' behaviour, especially the lowest income group. Among men who smoked in 2014, 35.85\% reported being affected by the 2015 increase in tobacco price. Indeed, $3.96 \%$ of male smokers quit smoking within 1 year due to the tax policy. The largest proportion $(22.48 \%)$ reduced the amount they smoked after the tobacco price increase, and another $9.41 \%$ switched to cheaper brands, started using e-cigarettes or made other changes. Notably, an additional $5.72 \%$ of men who smoked responded that they quit independent of the price increase. A more significant impact was observed on the lower income group. Even high-risk drinkers and those who experienced depression were significantly affected by the tax policy.

Our results were comparable to previous assessments of the effects of tax policy, which observed reductions in smoking prevalence and increased quitting. For example, a tax increase in New Zealand resulted in 2-4\% of smokers quitting. ${ }^{20}$ In Turkey, the 2010 tax policy was associated with a relative change of $14.6 \%$ in population smoking prevalence between 2008 and 2012, an average yearly change of $3.65 \% .^{21}$ Tax effects were mainly observed among lower income populations. ${ }^{3}{ }^{4}$ As we observed, more smokers chose other behavioural changes than quitting, ${ }^{22-24}$ especially those who engaged in highrisk drinking, or experienced high stress or depression. High-risk drinkers reported that they were less affected by tobacco price increases than non-high-risk groups but were more likely to switch to a cheaper brand or new type of tobacco compared with those who were unaffected and continued smoking group. These results support the findings of existing literature that tobacco tax increases are associated with smoking and drinking behaviours of smokers. ${ }^{2526}$ The effect of the tax policy was found to be greater in the group with the experience of depression than the group without the experience of depression. Compared with the unaffected and continued smoking, those who experienced depression were more likely to reduce the amount of tobacco or shift to other types of tobacco brands after the tax policy in the group with experiences of depression. There was no significant difference in the effect of the tobacco price increase between the group experiencing high-level and low-level stress. Compared with the unaffected and continued smoking, those who experienced the high-level stress more changed their smoking-related behaviour reducing the amount of tobacco or switching to the cheaper brands or new types of tobacco. Although it has been reported that there is an interaction between mental health and smoking, ${ }^{27} 28$ there were few studies about the specific impact of tobacco tax policy on smoker's mental health.

The effects of tax policy on smoking need to be assessed in the context of a broader tobacco control policy. Recently, there have been discussions regarding the tobacco endgame, which goes beyond conventional tobacco control. ${ }^{6}$ It is necessary to review existing policies and establish new evidence-based strategies, because it is difficult to lower smoking prevalence substantially below the current level using conventional means. ${ }^{10}$ In particular, tobacco tax policy, which is a top priority in tobacco control, needs to be repositioned within the framework of the endgame strategy. Generally, the overall effect of tax policy on the tobacco market and public health has been assessed based on the sales volume of cigarettes 
Table 4 Results of multinomial logistic regression analysis examining associations of changes in smoking behaviours with demographics and health-related behaviours

\begin{tabular}{|c|c|c|c|c|c|c|c|c|}
\hline \multirow[b]{2}{*}{ Variables } & \multicolumn{2}{|c|}{ Affected and quit } & \multicolumn{2}{|c|}{$\begin{array}{l}\text { Affected and reduced } \\
\text { smoking amount }\end{array}$} & \multicolumn{2}{|c|}{$\begin{array}{l}\text { Affected and changed } \\
\text { smoking behaviour in } \\
\text { other ways }{ }^{\star}\end{array}$} & \multicolumn{2}{|c|}{$\begin{array}{l}\text { Unaffected but quit } \\
\text { smoking }\end{array}$} \\
\hline & OR & $(95 \% \mathrm{Cl})$ & OR & $(95 \% \mathrm{Cl})$ & OR & $(95 \% \mathrm{Cl})$ & OR & $(95 \% \mathrm{Cl})$ \\
\hline \multicolumn{9}{|c|}{ Monthly household income (unit: million KRW) $†$} \\
\hline$<1$ (US\$845) & 1.98 & (1.54 to 2.54$)$ & 2.23 & (1.98 to 2.51$)$ & 1.69 & (1.43 to 2.00$)$ & 1.37 & (1.11 to 1.68$)$ \\
\hline$(1-1.99)$ & 1.29 & (1.05 to 1.58$)$ & 1.56 & (1.40 to 1.72$)$ & 1.58 & (1.37 to 1.82$)$ & 0.93 & (0.77 to 1.12$)$ \\
\hline$(2-2.99)$ & 1.05 & (0.87 to 1.26$)$ & 1.36 & $(1.24$ to 1.49$)$ & 1.25 & (1.11 to 1.41$)$ & 0.99 & (0.85 to 1.14$)$ \\
\hline$(3-3.99)$ & 1.02 & (0.86 to 1.21$)$ & 1.16 & $(1.06$ to 1.27$)$ & 1.13 & (0.99 to 1.29$)$ & 0.98 & (0.85 to 1.14$)$ \\
\hline$\geq 4$ (US\$3380) & 1.00 & (Ref) & 1.00 & (Ref) & 1.00 & (Ref) & 1.00 & (Ref) \\
\hline \multicolumn{9}{|l|}{ Age (years) } \\
\hline $19-29$ & 0.73 & (0.53 to 1.00$)$ & 0.76 & (0.63 to 0.90$)$ & 1.09 & (0.85 to 1.40$)$ & 0.96 & (0.71 to 1.29 ) \\
\hline $30-39$ & 0.57 & (0.43 to 0.76$)$ & 0.63 & (0.54 to 0.74$)$ & 0.99 & (0.78 to 1.24$)$ & 0.71 & (0.55 to 0.92 ) \\
\hline $40-49$ & 0.62 & (0.48 to 0.82 ) & 0.62 & (0.53 to 0.72 ) & 1.02 & (0.81 to 1.28$)$ & 0.54 & (0.42 to 0.69 ) \\
\hline $50-59$ & 0.63 & (0.49 to 0.82 ) & 0.67 & (0.58 to 0.78 ) & 1.16 & (0.94 to 1.44 ) & 0.60 & (0.48 to 0.76 ) \\
\hline $60-69$ & 0.88 & (0.69 to 1.12 ) & 0.83 & (0.72 to 0.95$)$ & 1.17 & (0.94 to 1.46 ) & 0.89 & (0.71 to 1.12 ) \\
\hline$\geq 70$ & 1.00 & (Ref) & 1.00 & (Ref) & 1.00 & (Ref) & 1.00 & (Ref) \\
\hline \multicolumn{9}{|l|}{ Education level } \\
\hline$\leq$ Middle school & 0.98 & (0.80 to 1.21 ) & 1.47 & (1.31 to 1.65$)$ & 1.55 & (1.32 to 1.81$)$ & 0.90 & (0.74 to 1.09 ) \\
\hline $\begin{array}{l}\text { Mid. sch. to } \\
\text { Univ. }\end{array}$ & 0.90 & (0.78 to 1.04 ) & 1.28 & (1.19 to 1.39 ) & 1.32 & (1.18 to 1.46 ) & 0.85 & (0.75 to 0.96 ) \\
\hline$\geq$ University & 1.00 & (Ref) & 1.00 & (Ref) & 1.00 & (Ref) & 1.00 & (Ref) \\
\hline \multicolumn{9}{|l|}{ Marital status } \\
\hline Single & 0.75 & (0.63 to 0.89 ) & 1.00 & (0.92 to 1.09 ) & 1.05 & (0.94 to 1.18 ) & 0.62 & (0.53 to 0.74$)$ \\
\hline Married & 1.00 & (Ref) & 1.00 & (Ref) & 1.00 & (Ref) & 1.00 & (Ref) \\
\hline \multicolumn{9}{|c|}{ Number of household members } \\
\hline One & 0.90 & (0.71 to 1.15$)$ & 0.79 & (0.71 to 0.89$)$ & 1.00 & (0.86 to 1.15$)$ & 1.08 & (0.88 to 1.33 ) \\
\hline Two & 1.09 & (0.93 to 1.26$)$ & 0.88 & (0.81 to 0.95$)$ & 1.06 & (0.95 to 1.18$)$ & 1.12 & (0.98 to 1.28$)$ \\
\hline Three or more & 1.00 & (Ref) & 1.00 & (Ref) & 1.00 & (Ref) & 1.00 & (Ref) \\
\hline \multicolumn{9}{|l|}{ Type of community } \\
\hline City (urban) & 1.16 & (1.02 to 1.32$)$ & 1.05 & (0.98 to 1.12$)$ & 0.99 & (0.91 to 1.08$)$ & 1.16 & (1.03 to 1.30$)$ \\
\hline Town (rural) & 1.00 & (Ref) & 1.00 & (Ref) & 1.00 & (Ref) & 1.00 & (Ref) \\
\hline \multicolumn{9}{|c|}{ High-risk alcohol drinking } \\
\hline Yes & 0.82 & (0.72 to 0.93 ) & 0.79 & (0.74 to 0.85$)$ & 1.11 & (1.02 to 1.21$)$ & 0.76 & (0.67 to 0.86$)$ \\
\hline No & 1.00 & (Ref) & 1.00 & (Ref) & 1.00 & (Ref) & 1.00 & (Ref) \\
\hline \multicolumn{9}{|l|}{ Physical activity } \\
\hline No & 0.92 & (0.80 to 1.05$)$ & 1.00 & (0.93 to 1.07$)$ & 0.97 & (0.89 to 1.07 ) & 0.94 & (0.84 to 1.06$)$ \\
\hline Yes & 1.00 & (Ref) & 1.00 & (Ref) & 1.00 & (Ref) & 1.00 & (Ref) \\
\hline \multicolumn{9}{|c|}{ Self-reported stress level } \\
\hline High & 0.74 & (0.65 to 0.85$)$ & 0.94 & (0.88 to 1.01$)$ & 1.19 & (1.09 to 1.30$)$ & 0.77 & (0.69 to 0.87 ) \\
\hline Low & 1.00 & (Ref) & 1.00 & (Ref) & 1.00 & (Ref) & 1.00 & (Ref) \\
\hline \multicolumn{9}{|c|}{ Experience of depression } \\
\hline Yes & 0.98 & (0.74 to 1.28$)$ & 1.23 & (1.09 to 1.40$)$ & 1.37 & (1.16 to 1.61$)$ & 0.98 & (0.76 to 1.26$)$ \\
\hline No & 1.00 & (Ref) & 1.00 & (Ref) & 1.00 & (Ref) & 1.00 & (Ref) \\
\hline \multicolumn{9}{|c|}{ Number of chronic diseasesł } \\
\hline Two or more & 1.12 & (0.94 to 1.34$)$ & 1.06 & (0.96 to 1.16$)$ & 1.05 & (0.92 to 1.19$)$ & 1.46 & (1.25 to 1.71$)$ \\
\hline
\end{tabular}




\begin{tabular}{|c|c|c|c|c|c|c|c|c|}
\hline \multirow[b]{2}{*}{ Variables } & \multicolumn{2}{|c|}{ Affected and quit } & \multicolumn{2}{|c|}{$\begin{array}{l}\text { Affected and reduced } \\
\text { smoking amount }\end{array}$} & \multicolumn{2}{|c|}{$\begin{array}{l}\text { Affected and changed } \\
\text { smoking behaviour in } \\
\text { other ways* }\end{array}$} & \multicolumn{2}{|c|}{$\begin{array}{l}\text { Unaffected but quit } \\
\text { smoking }\end{array}$} \\
\hline & OR & $(95 \% \mathrm{Cl})$ & OR & $(95 \% \mathrm{Cl})$ & OR & $(95 \% \mathrm{Cl})$ & OR & $(95 \% \mathrm{Cl})$ \\
\hline One & 1.11 & (0.97 to 1.27$)$ & 1.04 & (0.97 to 1.11$)$ & 1.05 & (0.95 to 1.15$)$ & 1.09 & (0.97 to 1.24$)$ \\
\hline Zero & 1.00 & (Ref) & 1.00 & (Ref) & 1.00 & (Ref) & 1.00 & (Ref) \\
\hline
\end{tabular}

*Other changes including 'switched to cheaper brands', 'switched to e-cigarettes', 'switched to non-cigarette tobacco products' and 'other'. †P for trend $<0.001$ of monthly household income as an ordinal variable: for 'affected and quit', $\mathrm{p}<0.001$; for 'affected and reduced smoking amount', $p<0.001$; for 'affected and changed smoking behaviour in other ways', $p=0.326$; for 'unaffected but quit smoking', adjusted for all other variables.

‡Doctor-diagnosed high blood pressure, diabetes, hypoglycaemic, arthritis, asthma, allergic rhinitis or atopic dermatitis.

or smoking prevalence. ${ }^{4}$ However, these economic and population-level indicators do not explain the effects on individual smokers' behaviours. For example, changes in sales quantity do not distinguish between people who are quitting and those who are merely reducing their smoking amount. Furthermore, a reduction in prevalence does not distinguish between the effects of tax and other policies. Therefore, it is necessary to study the impact of tax policy on individual smokers' behaviour. ${ }^{29}$ Using Korea as a case study, we compared smokers' behaviour before and after the implementation of a tax policy that sharply increased the price of tobacco nationwide. ${ }^{13}$

Based on our results, we suggest that the tax policy was effective but incomplete in three critical ways, particularly from the perspective of the tobacco endgame. In our discussion below, we adopt a perspective that assumes that smokers continue or quit smoking to maximise utility, which involves economic and non-economic aspects. ${ }^{24}$ First, tax policy is directed to increase the economic cost of smoking, which may be evaded without quitting. In our study, most smokers among the 'affected' group did not quit smoking but instead reduced their smoking amount or made other changes in their behaviours. The tax policy aims to make the cost of smoking exceed its utility, motivating smokers to quit or buy fewer cigarettes because of the economic burden of higher product price. ${ }^{30}$ However, smokers can buffer the policy effect by using cost-minimising strategies, ${ }^{23}$ such as reducing the smoking amount, switching to a cheaper brand or seeking other types of cigarettes with more cost-efficient satisfaction, such as a flavoured product, non-cigarette tobacco product or e-cigarettes. These mitigation possibilities may inherently limit the role of tax policy as society moves toward the endgame stage.

Second, tax policy does not tackle the nature of the addiction underlying smoking behaviour and thus is inefficient in motivating smokers to quit. Smoking involves costs such as health risks and the immediate expenditure to buy cigarettes and its utility as a consumption good or a socialising tool. ${ }^{31}$ According to the behavioural economics theory of addiction, smokers and other users of addictive goods have a rational basis to maximise their satisfaction. ${ }^{32} 33$ If the utility of quitting were higher than that of smoking, smokers would quit. However, there are unique characteristics of addiction that make this rational choice difficult. First, addiction exacerbates temporal discounting, leading to a lower valuation of the future health benefits than the present utility. ${ }^{34}$ Second, withdrawal symptoms cause significant disutility when attempts are made to quit. Thus, not only smoking but also quitting incurs costs, creating a barrier to any tax effects. Because of these features of addiction, tax policy will realise its full potential only if implemented in combination with a sufficient level of 'help provision' policies for nicotine dependence treatment.

Third, tax policy is not oriented to social and ethical values that go beyond economic rationales. Many quitters answered that they did not quit smoking because of the price increase. Instead, they stopped for their own health or that of their family. ${ }^{17}$ Health is a social value for the individual, their family and society. ${ }^{35}$ For many smokers, health may not be exchangeable for any amount of money. Some smokers quit because they did not want to cause trouble to people around them, for example, secondhand smoke. In other words, smokers did not choose to quit smoking merely because of the economic burden but also because they recognised social and ethical values associated with quitting smoking. Appreciation of the social value of quitting involves various perceptual factors, which non-tax policies can strongly influence. The tobacco endgame vision requires a social and ethical consensus that goes far beyond economic calculations and necessitates policy arrangements to complement the limits of tax policy.

There are specific ways to overcome the limitations of tax policy. First, the efficacy of tax policy can be strengthened by repetitive implementation, as exemplified in New Zealand, where the price was increased annually for 7 years starting in $2010 .^{7}$ If the tax policy is enforced repeatedly, less time may be allowed for cost-minimising adaptations, and adjustments can be made for inflation, keeping the price of cigarettes consistently high relative to the utility of smoking. More importantly, strategic planning is necessary to implement price and non-price policies together for maximum effect. ${ }^{10}$ The WHO recommends MPOWER measures as an effective tobacco policy. Combined 
policies decrease smoking by simultaneously influencing various factors. Raising the tobacco tax $(\mathrm{R})$ and warning against health hazards (W) increases the perceived costs of smoking. Regulating tobacco advertisement, promotion and sponsorship bans (E) prevent misleading depictions of the attractiveness of tobacco products. Offering cessation services $(\mathrm{O})$ reduces the disutility of withdrawal symptoms, and protecting people from tobacco smoke (P) reflects the social value of quitting.

Finally, an important approach to the tobacco endgame is to focus on the supply side. ${ }^{6}$ In the WHO FCTC, price and tax measures belong to the demand-reduction section; most other non-tax policies are also on the demand side. Fewer measures are listed in the supplycontrol section, and relatively less attention has been given to this side. Dismantling the supply chain ecosystem is crucial to winning the tobacco endgame, and intensive efforts are needed for this undertaking.

Our study had some limitations. First, our survey did not capture information on the amount of smoking or smoking frequency before the tax increase. Also, we assessed smoking-related behaviour changes over a relatively short period (during the past year); some quitters might have relapsed. Specific information was not available on the duration of quitting. Past smokers' recall of whether they quit within the past year or earlier might also have been inaccurate in some cases, although we believe that any such misclassification would not have seriously affected our findings. Despite these limitations, by retrospectively reconstructing a cohort study, our investigation provides insight into the behaviour changes of individual smokers following the implementation of a tobacco price increase. In this way, we were able to assess the reasons for quitting among those who stopped smoking. It should be noted that females were not included in this study. Smoking in women is an important issue not only because it affects their health ${ }^{36}$ but also because children and the elderly being cared for by women could be affected by secondhand smoke exposure. ${ }^{37}$ However, examining the effects of the tax policy on women would have required a much more in-depth analysis. Since the smoking prevalence of women is significantly lower than that of men in Korea, ${ }^{38}$ both genders need to be analysed separately. Moreover, previous studies reported that women may be more sensitive to tax increases. ${ }^{40}$ Exploring and testing for gender differences exceeded the focus of this paper and merits a separate study.

\section{CONCLUSION}

Korea's 2015 cigarette price increase policy had a significant impact on quitting rates, especially among those in the lowest socioeconomic group, and in high-risk drinkers and those experiencing depression. However, limitations of the tax policy were also observed, where many smokers could find ways to avoid the price burden without quitting. Notably, more smokers quit for reasons other than the increased price. Tobacco tax policy is an effective and essential means of tobacco control, but is insufficient in isolation for the tobacco endgame. It is necessary to develop a strategy for a comprehensive policy to overcome the limitations of tax policy and meet the goal of the tobacco endgame.

Contributors SK: Conceptualized the study, analyzed the data and wrote the manuscript as a guarantor. S-iC: Conceptualized the study, interpreted the results and helped to draft and revise the manuscript.

Funding The authors have not declared a specific grant for this research from any funding agency in the public, commercial or not-for-profit sectors.

Competing interests None declared.

Patient and public involvement Patients and/or the public were not involved in the design, or conduct, or reporting, or dissemination plans of this research.

Patient consent for publication Not applicable.

Ethics approval This study was approved by the Ethics Committee of Seoul National University (IRB No. E2102/003-004).

Provenance and peer review Not commissioned; externally peer reviewed.

Data availability statement Data are available in a public, open access repository. Data are available upon reasonable request. Data can be downloaded from KCDA Community Health Survey Homepage (https://chs.cdc.go.kr/chs/rawDta/ rawDtaProvdMain.do).

Open access This is an open access article distributed in accordance with the Creative Commons Attribution Non Commercial (CC BY-NC 4.0) license, which permits others to distribute, remix, adapt, build upon this work non-commercially, and license their derivative works on different terms, provided the original work is properly cited, appropriate credit is given, any changes made indicated, and the use is non-commercial. See: http://creativecommons.org/licenses/by-nc/4.0/.

ORCID iD

Seulgi Kim http://orcid.org/0000-0001-5530-0367

\section{REFERENCES}

1 Ngo A, Cheng K-W, Chaloupka FJ, et al. The effect of MPOWER scores on cigarette smoking prevalence and consumption. Prev Med 2017;105S:S10-14.

2 Parks MJ, Kingsbury JH, Boyle RG, et al. Behavioral change in response to a statewide tobacco tax increase and differences across socioeconomic status. Addict Behav 2017;73:209-15.

3 Jha P, Peto R. Global effects of smoking, of quitting, and of taxing tobacco. N Engl J Med 2014;370:60-8.

4 Chaloupka FJ, Straif K, Leon ME, et al. Effectiveness of tax and price policies in tobacco control. Tob Control 2011;20:235-8.

5 Townsend J, Roderick P, Cooper J. Cigarette smoking by socioeconomic group, sex, and age: effects of price, income, and health publicity. BMJ 1994;309:923-7.

6 McDaniel PA, Smith EA, Malone RE. The tobacco endgame: a qualitative review and synthesis. Tob Control 2016;25:594-604.

7 Cobiac LJ, Ikeda T, Nghiem N, et al. Modelling the implications of regular increases in tobacco taxation in the tobacco endgame. Tob Control 2015;24:e154-60.

8 Thomas BP, Gostin LO. Tobacco endgame strategies: challenges in ethics and law. Tob Control 2013;22 Suppl 1:i55-7.

9 Moon G, Barnett R, Pearce J, et al. The tobacco endgame: the neglected role of place and environment. Health Place 2018;53:271-8.

10 Myers ML. The FCTC's evidence-based policies remain a key to ending the tobacco epidemic. Tob Control 2013;22 Suppl 1:i45-6.

11 Rabe BG. Political impediments to a tobacco endgame. Tob Control 2013;22 Suppl 1:i52-4.

12 van Schalkwyk MCI, McKee M, Been JV, et al. Analysis of tobacco industry pricing strategies in 23 European Union countries using commercial pricing data. Tob Control 2019;28:e102-9.

13 Cherukupalli R. Korea's 2015 cigarette tax increases. Tob Control 2016;25:123-4.

14 Choi SE. Are lower income smokers more price sensitive?: the evidence from Korean cigarette Tax increases. Tob Control 2016;25:141-6.

15 Kwon DS, Kim TH, Byun MK, et al. Positive effects of the National cigarette price increase policy on smoking cessation in South Korea. Tuberc Respir Dis 2020;83:71-80. 
16 Kim I, Khang Y-H. Differential changes in quitting smoking by daily cigarette consumption and intention to quit after the introduction of a tobacco Tax increase and pictorial cigarette pack warnings in Korea, 2013-2017. Drug Alcohol Depend 2020;213:108085.

17 Han MA. The price of tobacco and its effects on smoking behaviors in Korea: the 2015 Korea community health survey. Prev Med 2019;120:71-7.

18 Kang YW, Ko YS, Kim YJ, et al. Korea community health survey data profiles. Osong Public Health Res Perspect 2015;6:211-7

19 Richardson S, Lin T, Li Y, et al. Guidance for use of weights: an analysis of different types of weights and their implications when using SAS PROCs. Gen Psychiatr 2019;32:e100038.

20 Li J, Newcombe R, Guiney H, et al. Impact on smoking behavior of the New Zealand annual increase in tobacco tax: data for the fifth and sixth year of increases. Nicotine Tob Res 2017;19:1491-8.

21 Kostova D, Andes L, Erguder T, et al. Cigarette prices and smoking prevalence after a tobacco tax increase--Turkey, 2008 and 2012. MMWR Morb Mortal Wkly Rep 2014;63:457-61.

22 Chen C-M, Chang K-L, Lin L, et al. Brand switching or reduced consumption? A study of how cigarette taxes affect tobacco consumption. Eur J Health Econ 2014;15:991-8.

23 Choi K, Boyle RG. Changes in cigarette expenditure minimising strategies before and after a cigarette Tax increase. Tob Control 2018;27:99-104.

24 Kostova D, Husain MJ, Chaloupka FJ. Effect of cigarette prices on smoking initiation and cessation in China: a duration analysis. Tob Control 2016;26:569-74.

25 Young-Wolff KC, Kasza KA, Hyland AJ, et al. Increased cigarette Tax is associated with reductions in alcohol consumption in a longitudinal U.S. sample. Alcohol Clin Exp Res 2014;38:241-8.

26 Krauss MJ, Cavazos-Rehg PA, Plunk AD, et al. Effects of state cigarette excise taxes and smoke-free air policies on state per capita alcohol consumption in the United States, 1980 to 2009. Alcohol Clin Exp Res 2014;38:2630-8.

27 Lawrence D, Mitrou F, Zubrick SR. Smoking and mental illness: results from population surveys in Australia and the United States. BMC Public Health 2009;9:285.
28 Ashton M, Rigby A, Galletly C. Do population-wide tobacco control approaches help smokers with mental illness? Aust N Z J Psychiatry 2014;48:121-3.

29 Bader P, Boisclair D, Ferrence R. Effects of tobacco taxation and pricing on smoking behavior in high risk populations: a knowledge synthesis. Int J Environ Res Public Health 2011;8:4118-39.

30 Zimring FE, Nelson W. Cigarette taxes as cigarette policy. Tob Control 1995;4:S25-35.

31 Park E-J, Park S, Cho S-il, et al. What cigarette price is required for smokers to attempt to quit smoking? findings from the ITC Korea waves 2 and 3 survey. Tob Control 2015;24 Suppl 3:iii48-55.

32 Becker GS, Murphy KM. A theory of rational addiction. J Polit Econ 1988;96:675-700.

33 Andersson L, Bask M, Melkersson M. Economic man and the consumption of addictive goods: the case of two goods. Subst Use Misuse 2006;41:453-66.

34 Bickel WK, Miller ML, Yi R, et al. Behavioral and neuroeconomics of drug addiction: competing neural systems and temporal discounting processes. Drug Alcohol Depend 2007;90 Suppl 1:S85-91.

35 Mariner WK, Annas GJ. A culture of health and human rights. Health Aff 2016;35:1999-2004

36 Park YS, Park S, Lee C-H. The attributable risk of smoking on allcause mortality in Korean: a study using KNHANES IV-VI (2007-2015) with mortality data. Tuberc Respir Dis 2020;83:268-75.

37 Kim YM, Cho SI, status S. Work-Life conflict, and mental health. Am $J$ Ind Med 2020;63:703-12.

38 Lee Y, Lee K-S. Factors related to smoking status among young adults: an analysis of younger and older young adults in Korea. $J$ Prev Med Public Health 2019;52:92-100.

39 Organization WH. WHO global report on trends in prevalence of tobacco smoking 2000-2025. second ed, 2018.

40 Ngo A, Fong GT, Craig LV, et al. Analysis of gender differences in the impact of taxation and taxation structure on cigarette consumption in 17 ITC countries. Int $J$ Environ Res Public Health 2019;16. doi:10.3390/ijerph16071275. [Epub ahead of print: $10 \mathrm{Apr}$ 2019]. 